\title{
A INFLUÊNCIA DE PAULO FREIRE NO ENSINO DE CIÊNCIAS E NA EDUCAÇÃO CTS: UMA ANÁLISE BIBLIOMÉTRICA
}

\author{
Gabriela Zauith ${ }^{1}$ \\ Maria Cristina Piumbato Innocentini Hayashi ${ }^{2}$
}

\section{RESUMO}

O Ensino de Ciências é um campo de pesquisa diferenciado por abordagens que se modificam de acordo com o contexto histórico, econômico e social em que está inserido. Dentre suas vertentes críticas, a Educação CTS (Ciência, Tecnologia e Sociedade) possui similaridades com a Pedagogia Libertadora de Paulo Freire quanto à educação política, nãobancária e contra-hegemônica. A partir da pesquisa bibliométrica realizada foram coletados dados no Banco de Teses da Capes e no Caderno de Indicadores Capes. O objetivo foi traçar o mapa da produção científica em Ensino de Ciências e Educação/Ensino CTS e identificar tendências e justificativas para utilização da abordagem freireana. $\mathrm{O}$ corpus da pesquisa foi constituído por 43 teses e dissertações de Ensino de Ciências e Educação CTS e bibliografias presentes em 22 disciplinas oferecidas em Programas de Pós-Graduação do país que utilizaram a perspectiva teórica freireana. As análises bibliométrica e de conteúdo dessa produção científica apontaram que a Educação CTS estabelece ligações concretas com a pedagogia de Paulo Freire por meio da utilização do seu referencial teórico nas teses e dissertações, bem como em disciplinas de pós-graduação, configurando um campo de pesquisa em construção, situado em instituições de renome, como UFSC, USP e UnB.

Palavras-Chave: Ensino de Ciências; Movimento CTS; Paulo Freire; produção científica.

\section{THE INFLUENCE OF PAULO FREIRE IN SCIENCE EDUCATION AND STS EDUCATION: A BIBLIOMETRIC ANALYSIS}

\begin{abstract}
The teaching of science is a field of research by different approaches that change according to the historical context, economic and social environment in which it operates. Among its critical aspects, STS Education (Science, Technology and Society) has similarities with the Liberation Pedagogy of Paulo Freire on education policy, non-bank and counter-hegemonic. From the research conducted bibliometric data were collected in Theses Database of Capes (Banco de Teses da Capes) and Capes Notebook Indicators (Caderno de Indicadores Capes). The objective was to map the scientific production in the Teaching of Science and Education / STS Teaching and identify trends and justification for use of Freire's approach. The research corpus consisted of 43 theses and dissertations for Science Teaching and STS Education and bibliographies present in 22 subjects offered in the Graduate Programs in the country that used the Freire's theoretical perspective. The bibliometric analysis and content of this scientific production showed that the STS Education establishes concrete links with the pedagogy of Paulo Freire by using their theoretical theses and dissertations, as well as graduate courses. Setting up a search field under construction, located at renowned institutions such as UFSC, USP and UnB.
\end{abstract}

Keywords: Science Education; STS Movement; Paulo Freire; scientific production 


\section{Introdução}

O Ensino de Ciências é um campo de pesquisa diferenciado por abordagens que se modificam de acordo com o contexto histórico, econômico e social em que está inserido. A discussão da ciência e da tecnologia no campo educacional é tema de pesquisas desde a década de 1960, do século passado, em países do hemisfério norte, como Espanha, Reino Unido, Canadá e EUA integrando o campo Ciência, Tecnologia e Sociedade (CTS), e dando origem à denominação Educação $\mathrm{CTS}^{3}$.

No Brasil, o campo teórico abrange o Ensino de Ciências nas áreas da Física, Química, Biologia e Matemática, na educação básica, superior e na educação de jovens e adultos, orientado por pesquisas de Demétrio Delizoicov (UFSC), Décio Auler (UFSM), Irlan von Linsingen (UFSC) e Wildson Pereira dos Santos (UnB).

O enfoque de Paulo Freire na educação científica já se estabelece como campo de ensino e pesquisa, quando salienta aspectos da educação política, não-bancária e contrahegemônica. Ligação que ocorre por meio de três sistemáticas que relacionam a pedagogia freireana com a Educação CTS: palavras geradoras e investigação temática; educação política e participação pública e educação problematizadora e não-neutralidade da concepção de ciência.

O pensamento de Paulo Freire e a evolução do próprio Ensino de Ciências são marcados por acontecimentos históricos, a partir de marcos definidos entre 1950 e 2000 . No Ensino de Ciências, Krasilchik (2000) relaciona acontecimentos históricos de enfoque mundial como a Guerra Fria, a Guerra Tecnológica e a Globalização. De forma semelhante, o pensamento de Paulo Freire foi abordado de acordo com o contexto político brasileiro: Populismo, Ditadura Militar e Nova República.

Trata-se de uma pesquisa exploratória e descritiva, e para compor o campo de pesquisa estudado foi utilizada a abordagem bibliométrica. Por meio dessa metodologia que utiliza métodos estatísticos para quantificar a produção de documentos refletida nas bibliografias - é possível compreender o processo de constituição de um campo científico. (SILVA, HAYASHI, HAYASHI, 2011). As fontes de dados da pesquisa foram a) teses e dissertações cadastradas no Banco de Teses da Capes; e b) disciplinas de pós-graduação e suas respectivas bibliografias disponíveis no Caderno de Indicadores Capes. Para relacionar dados do Banco de Teses e dos Cadernos de Indicadores, analisou-se dos dados da UFSC, UNB e USP nas disciplinas de seus programas de pós-graduação que enfocam o referencial teórico freireana e/ou que indicam em suas bibliografias obras de Paulo Freire.

O artigo está estruturado em seis partes, além dessa introdução. Na primeira dissertase sobre a teoria do Ensino de Ciências e Educação CTS, de acordo com tendências de ensino. Posteriormente apresenta-se a pedagogia de Paulo Freire, construída a partir de seus momentos históricos. Em seguida é feita a ligação do referencial de Paulo Freire e o Ensino de Ciências. Por fim os procedimentos metodológicos, e os resultados obtidos são descritos e analisados e as reflexões finais encerram o artigo.

\section{Ensino de Ciências e Educação CTS}

No Brasil assim como em outros países latino-americanos, europeus e norteamericanos, o Ensino de Ciências se adapta e se molda ao contexto social e econômico e ao 
desenvolvimento científico e tecnológico, bem como às relações sociais e históricas estabelecidas (Quadro 1).

Krasilchik (2000) afirma que a partir do momento em que ciência e a tecnologia foram reconhecidas como essenciais no desenvolvimento econômico, cultural e social, a educação deveria acompanhar essa evolução. Em decorrência desse avanço, na última década ocorreram diversas mudanças na base curricular do ensino nacional, entre elas a criação dos Parâmetros Curriculares Nacionais (PCN).

Na evolução da ciência ao longo de tempo, a neutralidade é um conceito que tem se modificado. "Na fase dos projetos de $1^{a}$ geração, a Ciência era considerada uma atividade neutra, isentando os pesquisadores de julgamento de valores sobre o que estavam fazendo". (KRASILCHIK, 2000, p.89). O crescimento de problemas sociais, crises ambientais, poluição, crise energética, movimentos sociais e estudantis, e lutas anti-segregação racial foram determinantes para transformações nas propostas das disciplinas científicas em todos os níveis do ensino, conforme sintetizado no Quadro 1.

Quadro 1 - Evolução das tendências no ensino segundo a situação mundial no período 1950-2000.

\begin{tabular}{|l|l|l|l|}
\hline \multirow{2}{*}{$\begin{array}{c}\text { TENDENCIAS NO } \\
\text { ENSINO }\end{array}$} & \multicolumn{3}{|c|}{ SITUAÇÃO MUNDIAL } \\
\cline { 2 - 4 } Objetivo do ensino & \multicolumn{1}{|c|}{$\begin{array}{c}1950 \\
\text { Guerra Fria }\end{array}$} & \multicolumn{1}{|c|}{$\begin{array}{c}1970 \\
\text { Guerra Tecnológica }\end{array}$} & \multicolumn{1}{c|}{$\begin{array}{c}1990-2000 \\
\text { Globalização }\end{array}$} \\
\hline Formar elite & $\begin{array}{l}\text { Formar cidadão- } \\
\text { trabalhador } \\
\text { Propostas Curriculares } \\
\text { Estaduais }\end{array}$ & $\begin{array}{l}\text { Formar cidadão- } \\
\text { trabalhador-estudante } \\
\text { Parâmetros } \\
\text { Curriculares Federais }\end{array}$ \\
\hline Concepção de ciência & Atividade neutra & $\begin{array}{l}\text { Evolução histórica } \\
\text { Pensamento lógico-crítico }\end{array}$ & $\begin{array}{l}\text { Atividade com } \\
\text { implicações sociais }\end{array}$ \\
\hline $\begin{array}{l}\text { Instituições promotoras de } \\
\text { reforma }\end{array}$ & $\begin{array}{l}\text { Projetos curriculares } \\
\text { Associações profissionais }\end{array}$ & $\begin{array}{l}\text { Centros de ciências } \\
\text { Universidades }\end{array}$ & $\begin{array}{l}\text { Universidades e } \\
\text { associações } \\
\text { profissionais }\end{array}$ \\
\hline $\begin{array}{l}\text { Modalidades didáticas } \\
\text { recomendadas }\end{array}$ & Aulas práticas & Projetos e discussões & $\begin{array}{l}\text { Jogos: exercícios no } \\
\text { computador }\end{array}$ \\
\hline
\end{tabular}

Fonte: KRASILCHIK (2000, p.86).

Nas décadas de 1950 e 1960, o Ensino de Ciências refletiu a situação do mundo ocidental após a II Guerra Mundial. Instituições educacionais elaboraram grandes projetos curriculares. No Brasil, no início dos anos 1950, criou-se o Instituto Brasileiro de Educação Ciência e Cultura (IBECC), que tinha como objetivo melhorar o Ensino de Ciências, transmitir informações, conceitos e fenômenos, descrevendo os produtos da ciência (KRASILCHIK, 1987). A relação da ciência com o contexto econômico, social e político não era discutida, nem mesmo aspectos tecnológicos e as aplicações práticas (FONSECA, 2008).

Como resultado das transformações políticas no período da Guerra Fria, entre 1960 e 1970, a influência no Ensino de Ciências passa a ser principalmente dos Estados Unidos, de onde surgiram mudanças curriculares com a substituição de métodos expositivos pelos métodos ativos e de aulas práticas com o uso do laboratório. O objetivo era vivenciar o método científico, pensar logicamente e racionalmente. Destaque para criação dos Centros de Ciências, conveniados com universidades para produção de materiais atualizados e 
complementares. No Brasil, com a criação da LDB (Lei de Diretrizes e Bases da Educação), em dezembro de 1961, que alterava o currículo de ciências, enfatizando uma postura de investigação (KRASILCHIK, 1987), o ensino de ciências toma outros rumos.

Nas décadas de 1970 e 1980 os problemas ambientais estavam no foco das discussões sobre o desenvolvimento científico. No projeto de Ciência Integrada, disseminado pela UNESCO, o Ensino de Ciências deveria ser estruturado para formação comum e posteriormente especializar-se em Física, Química, Biologia ou Matemática. A ideia era tornar possível o enfoque unificado dos problemas de natureza científica, permitir a compreensão do papel e da função da ciência na vida diária dos estudantes, organizar estudos de ciências em torno de temas e tópicos dotados de caráter unificador e evitar a duplicação de conteúdos presentes nas programações escolares (KRASILCHIK, 1987). Surgem as preocupações com as interações entre a ciência, tecnologia e sociedade e suas repercussões no Ensino de Ciências. Conceitos como paradigma, ciência normal e revoluções científicas foram praticamente ignorados na década de 1970 (FONSECA, 2008).

Nos Estados Unidos, Inglaterra e outros países europeus, entre 1980 e 1985, crescia o debate sobre a preocupação do Ensino de Ciências, voltado para a formação do cidadão, com o slogan "ciências para todos". Incorporava-se uma visão de ciência como atividade humana historicamente determinada, articulada entre o senso comum e o conhecimento científico. A partir desse momento começou a ser levado em conta o conhecimento prévio e as estruturas cognitivas do aluno. As discussões pareciam convergir para as interações entre os aspectos da ciência, tecnologia e sociedade no ensino das disciplinas científicas. As mudanças curriculares nos municípios e estados brasileiros ocorridas entre os anos 1980 e início dos anos 1990 absorveram essas influências e as incorporaram. Na visão de Fonseca (2008), o objetivo era contribuir para a formação da cidadania, no momento histórico do país de transformações políticas e busca pela justiça social.

A exclusão social, a luta pelos direitos humanos e a conquista da melhora da qualidade de vida não podem ficar à margem dos currículos e, no momento, assumem uma importância cada vez mais evidente. Pela demanda de justiça social nos atuais parâmetros curriculares, muitas das temáticas vinculadas no ensino de Ciências são hoje consideradas "temas transversais": educação ambiental, saúde, educação sexual. No entanto, a tradição escolar ainda determina que a responsabilidade do seu ensino recaia basicamente nas disciplinas científicas, principalmente a Biologia (KRASILCHIK, 2000, p.89).

O modelo CTS como forma de aprendizagem se estabelece no campo teórico com vistas a mudanças curriculares, observadas nos Parâmetros Curriculares Nacionais (PCN) e nos temas transversais da proposta curricular de Ciências Naturais. "Assim, as tendências para o Ensino de Ciências da década de 90 são marcadas pela importância atribuída à História e Filosofia da Ciência, a ênfase CTS dada à urgência da alfabetização científica para aproximação entre a ciência e o cidadão comum" (FONSECA, 2008, p.63).

Característica da década de 1990, a competição tecnológica, em especial no campo das tecnologias da comunicação e informação, estabeleceu novas prioridades. A transição política e a competição de mercado demandava mão de obra qualificada, e o "ensino de qualidade" passou a ser prioridade nas políticas governamentais. Formaram-se parcerias 
entre as Secretarias de Educação e as universidades para a elaboração de novos currículos e cursos de capacitação de professores em serviço (FONSECA, 2008).

Outra tendência no contexto de mudanças políticas e sociais é a concepção crítica do ensino e da própria ciência com o pensamento de Paulo Freire. Sua pedagogia influenciou duas linhas de investigações no Ensino de Ciências: a interdisciplinaridade e o trabalho com aspectos do cotidiano e da realidade de onde está localizada a escola (FONSECA, 2008).

\section{A trajetória histórica do pensamento de Paulo Freire}

A reflexão sobre o pensamento de Paulo Freire (1921-1977) a partir de obras selecionadas, somadas às indicações de sua biografia, vivências e parcerias, traz à tona a totalidade de seu pensamento, numa dimensão histórica e social, estabelecida em três momentos de sua produção intelectual: 1) A República Populista e o período de formação (1945-1964), 2) Regime militar e exílio (1964-1985); e 3) Nova República: o retorno (19852000), períodos representados de acordo com acontecimentos históricos, conforme detalha o Quadro 2.

\begin{tabular}{|c|c|c|c|}
\hline Situação Mundial & $\begin{array}{c}\text { Período de Formação } \\
\text { 1945-1964 } \\
\text { República Populista }\end{array}$ & $\begin{array}{c}\text { Exílio } \\
\text { 1965-1985 } \\
\text { Ditadura Militar }\end{array}$ & $\begin{array}{c}\text { Retorno ao país } \\
\text { 1986-2000 } \\
\text { Nova República }\end{array}$ \\
\hline Objetivo do ensino & $\begin{array}{l}\text { Educação } \\
\text { bancária/educação } \\
\text { libertadora }\end{array}$ & Educação política & Escola pública popular \\
\hline Concepção de ciência & $\begin{array}{l}\text { Dialética } \\
\text { Opressor/oprimido }\end{array}$ & Invasão cultural & $\begin{array}{l}\text { Pensamento analítico } \\
\text { histórico }\end{array}$ \\
\hline Instituições & $\begin{array}{l}\text { Escola como forma de } \\
\text { participação } \\
\text { democrática }\end{array}$ & $\begin{array}{l}\text { Círculos de cultura- } \\
\text { educação de jovens e } \\
\text { adultos }\end{array}$ & $\begin{array}{l}\text { A escola vista como um } \\
\text { todo }\end{array}$ \\
\hline Conceitos & $\begin{array}{l}\text { Trabalho educativo } \\
\text { crítico }\end{array}$ & $\begin{array}{l}\text { Diálogo e } \\
\text { problematização } \\
\text { Consciência crítica } \\
\text { torna-se consciência } \\
\text { revolucionária }\end{array}$ & $\begin{array}{l}\text { Saber feito de } \\
\text { experiência }\end{array}$ \\
\hline Obra emblemática & $\begin{array}{l}\text { Educação e Atualidade } \\
\text { Brasileira (1959) }\end{array}$ & $\begin{array}{l}\text { Pedagogia do oprimido } \\
\text { (1970) }\end{array}$ & $\begin{array}{l}\text { A educação na cidade } \\
\text { (1991) }\end{array}$ \\
\hline
\end{tabular}

Elaboração das autoras

\subsection{A República Populista e o período de formação}

Desde a infância Paulo Freire vivenciou concretamente suas questões de luta contra a sociedade hegemônica e a favor dos desfavorecidos. Com uma infância rica de vivências e brincadeiras, foi educado e alfabetizado entre mangueiras do seu quintal, com palavras e frases ligadas ao seu cotidiano. A primeira grande mudança em sua vida ocorreu durante o período de crise em 1929, fazendo com que sua família sentisse a mudança na escala social para o nível da pobreza, período em que também perdeu seu pai. A mudança para Jaboatão (Pernambuco) se deu um espaço-tempo de aprendizagem, de dificuldades e de alegrias 
vividas intensamente, as quais lhe ensinaram "a harmonizar o equilíbrio entre o ter e o nãoter, o ser e não-ser, o poder e não-poder, o querer e não-querer" (GADOTTI, 1996, p. 30).

A primeira escola - local onde posteriormente foi professor-, foi encontrada com dificuldade por sua mãe devido à situação financeira que enfrentavam. A amorosidade com sua primeira professora instigou o fascínio pela língua portuguesa, característica que permeia toda sua obra, com uma escrita visceral, atenta à grafia e ao significado das palavras. Sem a possibilidade de cursar pedagogia, cursou direito, a carreira mais próxima da área das humanas, profissão que não exerceu.

Como educador no Serviço Social da Indústria (SESI) esteve à frente de projetos, dentre eles de educação de adultos e trabalhadores, como diretor do setor de Educação e Cultura. Viajou e conheceu o sofrimento e o conhecimento do povo brasileiro. Nas escolas observava a prática educativa e as dificuldades encontradas pelas famílias das áreas populares. Sua busca era por um diálogo e pela participação democrática de pais e mães na política educacional (FREIRE, 1992).

Suas práticas vividas foram confirmadas ao longo de sua experiência profissional. "Você só trabalha realmente em favor das classes populares se você trabalha com elas, discutindo com respeito seus sonhos, seus desejos, suas frustrações, seus medos, suas alegrias" (FREIRE, 2007, p.42). A convivência com a classe popular instigou sua revolta com a desumanização e com preconceitos, gestando pensamentos de humanidade. "Menino, cedo desafiado pelas injustiças sociais como cedo se tomando de raiva contra preconceitos raciais e de classe a que juntaria mais tarde outra raiva, a raiva dos preconceitos em torno do sexo e da mulher" (FREIRE, 2007, p.40).

O educador Paulo Freire, de projeção nacional, destacou-se nos estudos sobre a educação de adultos no Seminário Regional de Educação de Adultos, em Pernambuco. Posteriormente, engajou-se no Movimento de Cultura Popular (MCP), da Prefeitura de Recife. A aplicação de seu método de alfabetização de adultos, com uma experiência inovadora em Angicos (Pernambuco), fez com que, em 1964 coordenasse o Programa Nacional de Alfabetização alfabetizando cinco milhões de adultos. O Programa foi extinto três meses depois pelo governo militar. Mais que um método de alfabetização, uma compreensão dialética da educação preocupada com o processo de conhecer em que educadores e educandos devem assumir o papel crítico de sujeitos aptos ao conhecimento, isto é, cognoscentes.

A sua carreira como professor universitário iniciou em 1959, momento em que defendeu sua tese em Filosofia e História da Educação e intitulada Educação e atualidade brasileira (FREIRE, 1959), que busca compreender a contraditória sociedade brasileira, visando a transformação social pelo povo. Posteriormente tornou-se professor efetivo na Faculdade de Filosofia e Letras da Universidade de Recife, onde também foi nomeado livredocente da Escola de Belas Artes.

O pensamento de Freire no período do populismo no Brasil possui reflexões que abordam as ambiguidades ao fazer intencionalmente emergir o povo na política apenas como base social de sustentação eleitoral, desprovido de forças de reação (FREIRE, 1979a). Passagem essa que foi de extrema importância para maturação das ideias apresentadas no seu primeiro livro, Pedagogia do Oprimido (FREIRE, 1983a), também encontradas em sua tese defendida na Universidade de Recife. 


\subsection{Ditadura militar e exílio}

Durante o período da Ditadura Militar, Freire é preso, refugiado na Bolívia e exilado no Chile com sua família. O fato de ter coordenado campanhas de alfabetização representava uma ameaça aos interesses da elite. Como "educador pelo mundo" passou também pelos Estados Unidos e Suíça, onde trabalhou como professor em universidades e escreveu várias obras.

No Chile permaneceu por quatro anos e meio, trabalhando em um instituto governamental chamado ICIRA (Instituto de Pesquisa e Treinamento em Reforma Agrária) e, também no órgão governamental, "Escritório Especial para a Educação de Adultos" (GADOTTI, 1996). A partir de sua estadia no Chile, Paulo Freire escreveu em 1969 a obra Extensão ou Comunicação? que reflete parte de seu trabalho com trabalhadores rurais. Freire escreveu esse livro aos agrônomos - o técnico em contato com o camponês - mas devido a seu conteúdo pertinente à problemática da reforma agrária o livro se tornou uma leitura abrangente ao tema da extensão agrícola como forma impositiva e manipuladora de educação (FREIRE, 1983b).

O processo de aprendizagem só ocorre verdadeiramente quando o educando é desafiado e se apropria do apreendido. A capacitação técnica deve estar contextualizada na realidade cultural e na vivência os camponeses. A extensão como invasão cultural é uma atitude contrária ao diálogo e favorável à dominação no âmbito da educação tradicional. Qualquer que seja o conteúdo, comercial ou técnico, este é sempre domesticador. Como educador, recusa o conceito de extensão e apresenta o de comunicação.

Se o conhecimento científico e a elaboração de um pensamento rigoroso não podem prescindir de sua matriz problematizadora, a apreensão deste conhecimento científico e do rigor deste pensamento filosófico não pode prescindir igualmente da problematização que deve ser feita em torno do próprio saber que o educando deve incorporar (FREIRE, 1983b, p.54).

\subsection{O retorno e a redemocratização}

No período de abertura política, Freire retorna ao Brasil em 1979 como professor na PUC/SP, Unicamp, e depois na Universidade Federal de Pernambuco, onde permaneceu até se aposentar. Após a morte de sua primeira esposa Elza Maria Costa de Oliveira com quem teve cinco filhos, Maria Madalena, Maria Cristina, Maria de Fátima, Joaquim e Lutgardes, casou-se novamente com Ana Maria Araújo, sua ex-aluna. Ambas as mulheres eram professoras e tiveram grande influência em sua vida e obra.

Em 1989 foi nomeado Secretário da Educação do Município de São Paulo em 1989, a partir da eleição de Luiza Erundina, do Partido dos Trabalhadores (PT), do qual foi um dos fundadores (ROMÃO, 2007).

Neste período publicou A educação na cidade (FREIRE, 1991), livro baseado em suas atividades como Secretário. Freire fez uma administração vigorosa, com o "corpo no mundo", e junto com sua equipe de trabalho decidia democraticamente metas e objetivos. "Não passou tanto tempo refletindo teoricamente sobre o poder ou teorizando sobre a politicidade da educação, mas exercendo o poder - sem bem que delimitado ou fragmentado" (FREIRE, 1991, p.13). Durante sua administração ampliou do acesso e a 
permanência dos setores populares; favoreceu a democratização do poder pedagógico entre professores, técnicos, funcionários e pais de família; colaborou para construção de um currículo interdisciplinar e formação docente permanente e por fim a lutou conta o analfabetismo de jovens e adultos, criando o Movimento de Alfabetização de Jovens e Adultos de São Paulo, o MOVA/SP (FREIRE, 1991).

Freire (1991) discorre sobre a "escola pública popular" democrática e com a participação de toda comunidade. A participação popular seria a responsável pela irradiação da cultura popular e espaço para debates, ideias, soluções e reflexões. Assim, rompe a tradição de que só a elite é competente e sabe quais são os interesses de toda comunidade. A qualidade dessa escola deverá ser medida não apenas pela quantidade de conteúdos transmitidos e assimilados, mas igualmente pela solidariedade de classe, pela possibilidade que todos os usuários da escola - incluindo pais e a comunidade - tiverem de utilizá-la como um espaço para elaboração de sua cultura (FREIRE, 1991).

Uma escola pública competente respeita seus padrões culturais de classe, seus valores, sua sabedoria, sua linguagem. Essa diferença na forma de apreensão da realidade, de uma criança favorecida com o hábito da leitura e do estudo, e de uma popular, que não possui essa habilidade, mas possui outras. Isso não determina sua "incompetência absoluta". Trata-se de uma capacidade que pode ser apreendida. Freire tinha o sonho de semear palavras em áreas populares - como fazem os grafiteiros - e em áreas de memória preponderantemente orais. Para um educador progressista, o "saber experiência feito" não pode ser desprezado. É a partir dele que se alcança o mais exato (FREIRE, 1991). "É a escola que estimula o aluno a perguntar, a criticar, a criar; onde se propõe a construção do conhecimento coletivo, articulando o saber popular e o saber crítico, científico, mediados pelas experiências no mundo" (FREIRE, 1991, p.83).

\section{Freire e o Ensino de Ciências}

A reflexão crítica da Educação CTS possui ressonância na Pedagogia Libertadora de Paulo Freire, campos complementares ao assumirem uma "perspectiva política no ensino de ciências" (SANTOS, 2008, p.119). A educação científica na maioria das escolas pode ser considerada como a educação bancária da concepção freireana, com a memorização de termos, sistemas e classificações. Educação neutra, não problematizadora, carrega consigo valores dominantes da tecnologia que têm submetido os interesses humanos àqueles puramente de mercado. Por isso, acaba sendo opressora, na medida em que reproduz um valor de ciência como um bem em si mesmo a ser consumido e aceito sem questionamentos (AULER; DELIZOICOV, 2006a).

Santos (2008, p. 111) traz a perspectiva educacional de Paulo Freire como uma visão humanística ao Ensino de Ciências, indo além das visões reducionistas do movimento CTS. "A perspectiva freireana traz a educação política que busca a transformação do modelo racional de ciência e tecnologia excludente para um modelo voltado para justiça e igualdade social". Ao pensar numa proposta CTS na perspectiva freireana, deve-se olhar para o processo de globalização, o que desencadearia um processo de opressão. $\mathrm{O}$ autor expõe uma proposta CTS freireana na discussão de aspectos da exclusão tecnológica.

Entretanto, algumas divergências consideram que o Movimento CTS repercute em contextos em que as condições materiais da população estão satisfeitas. Situação contrária à 
realidade da maioria dos países da América Latina, cuja população sofre por carências materiais básicas. Auler e Delizoicov (2006b) se referem ao passado de colonização, que possui renossância com a pedagogia de Paulo Freire.

Outra questão está relacionada ao estudo de temas. Na perspectiva de Freire os temas de aprendizagem surgem com uma efetiva participação da comunidade escolar. Enquanto que nos encaminhamentos dados pelo enfoque CTS essa dinâmica está ausente, sendo definida pelo professor. "Nos pressupostos freireanos, os temas são constituídos de manifestações locais de contradições maiores presentes na dinâmica social. Os temas do enfoque CTS são de abrangência mais geral, e não vinculados a contextos específicos" (AULER; DALMOLIN; FENALTI, 2009, p.79). Na visão de Santos (2008, p.120)

Enquanto Freire (1970) se concentra em uma visão humanística para as condições existenciais; CTS, na sua visão clássica, está centrado nas questões ambientais e no desenvolvimento de habilidades para a argumentação e a participação. $\mathrm{O}$ foco do trabalho de Freire está no HOMEM. Para ele, os temas geradores devem ter origem na sua situação presente, existencial, concreta dos educandos, refletindo suas aspirações.

A ligação do referencial em Paulo Freire e da abordagem CTS ocorre por diversas maneiras, dentre elas as que relacionam conceitos de ambas as vertentes: a) palavras geradoras e investigação temática; b) educação política e participação pública; e c) educação problematizadora de Freire e a não-neutralidade da concepção de ciência.

$\mathrm{Na}$ educação bancária, Freire critica que os conteúdos abordados em sala de aula estão distantes da realidade dos educandos, selecionados exclusivamente pelo professor. Em seu método de alfabetização de adultos são identificadas as palavras geradoras, temas que fazem sentido para aquela comunidade, um "pensamento linguagem" que contenha sua visão de mundo (FREIRE, 1979b). O enfoque CTS como o método de investigação temática "rompe com o tradicionalismo curricular do Ensino de Ciências uma vez que a seleção de conteúdos se dá a partir da identificação de temas que contemplem situações cotidianas dos educandos" (NASCIMENTO; von LINSINGEN, 2006, p.9).

Na questão da participação pública da Educação CTS e a educação política de Freire, o conhecimento mediado pelo diálogo possibilita uma "imersão", isto é, a possibilidade de mudança frente a uma situação opressora. Na educação praticada nas escolas, Freire aborda um problema fundamental sobre os conteúdos e indaga quem os escolhe, a favor de quem, contra quem (FREIRE, 1992, p. 110). Na abordagem CTS, a participação pública é referente ao modelo de comunicação pública da ciência, baseado no modelo democrático (DURANT, 1999). O objetivo é promover a participação em diversas esferas, como júris populares, debates e conferências de consenso, com o propósito de facilitar a comunicação entre governo e a diversidade de grupos sociais (OSÓRIO, 2005).

Em outra abordagem de participação, Santos e Mortimer (2002, p. 5) apontam os interesses coletivos e de consciência do compromisso social como um questionamento à ordem capitalista. A discussão de valores contribui para formação de cidadãos críticos e comprometidos com a sociedade.

A educação problematizadora de Freire se encontra com a não-neutralidade da concepção de ciência enquanto produto de interações sociais. Para Freire (2001), não pode existir "prática educativa neutra, descomprometida, apolítica". Na Educação CTS são 
apresentadas visões críticas da ciência, na busca de "desfazer o mito do cientificismo que ideologicamente ajudou a consolidar a submissão da ciência aos interesses de mercado, à busca do lucro" (SANTOS; MORTIMER, 2002, p.6).

Delizoicov e Auler (2011, p.248) situam que a reflexão epistemológica contemporânea já superou a concepção de neutralidade do conhecimento científico. Entretanto, a compreensão de uma Ciência neutra ainda está presente na academia, nos laboratórios de pesquisa e na educação científica básica. A produção da pesquisa científica está relacionada a dimensões espaço-temporais que se relacionam com o processo de produção de conhecimentos científico-tecnológicos, e não apenas com seu produto. A criação das teorias científicas adquirem intenções oriundas do processo, deixando de ser atemporais para possuírem historicidade. "A especificidade de um determinado espaçotempo, em que são localizados, formulados e enfrentados os problemas de CT [Ciência e Tecnologia], parece influir diretamente no que é produzido" (DELIZOICOV; AULER, 2011, p.216).

A demanda para as pesquisas em Ciência e Tecnologia ocorre por meio da seleção de problemas a serem investigados, os quais são determinados por fatores como interesses e necessidades, muitas vezes externos ao mundo científico. Nesse sentido, Delizoicov e Auler (2011) argumentam que na investigação temática de Freire, proveniente da problematização, pode-se identificar no processo dialógico as demandas e temáticas específicas próprias de uma comunidade.

Após essa breve exposição, em que buscamos apontar os pontos de confluência entre a pedagogia freireana, o Ensino de Ciências e a Educação CTS, é exposto o percurso metodológico adotado para identificar a presença do referencial teórico freireano na produção científica de teses e dissertações e nas disciplinas ministradas em programas de pós-graduação do país.

\section{Procedimentos metodológicos}

A presente pesquisa configura-se como exploratória e descritiva, e recorre à Bibliometria como metodologia. A análise bibliométrica é um método flexível e dinâmico que avalia a tipologia, a quantidade e a qualidade das fontes de informação. Com objetivo de documentar a produção científica é também uma forma de avaliação da própria ciência produzida, seja os próprios pesquisadores e seus programas de pós-graduação, universidades. É útil, em especial, para mapear áreas em construção, como é o caso da Educação e do Ensino CTS, ambos inseridos na grande área do Ensino de Ciências.

Com estudos iniciados na década de 1960, a Bibliometria se tornou nas últimas décadas uma importante ferramenta para o desenvolvimento da ciência. Com variados métodos de coleta de dados é considerada uma pesquisa interdisciplinar com a utilização de métodos estatísticos e na confluência da Sociologia da Ciência A aplicação de seus resultados principalmente na política científica possibilita a ampliação de estudos bem como o conhecimento de um campo a ser desenvolvido. A pesquisa em Bibliometria permite demarcar tendências e construir indicadores de uma determinada área do saber e a disponibilidade de novas fontes de informação sobre comunicação na web e em bibliotecas digitais ampliou o seu alcance. (GLÄNZEL, 2003; THELWALL, 2008) 
O princípio da Bibliometria consiste em analisar a atividade científica ou técnica pelos estudos quantitativos das publicações. Pode ser aplicada na seleção de livros e publicações periódicas, na identificação de temáticas da literatura, e na evolução de bibliografias e coleções. O objetivo é mapear a literatura de campos científicos ou de assuntos específicos dentro de uma área de conhecimento; verificar a produtividade de autores; a obsolescência da literatura, citar frentes de pesquisa e a analisar periódicos de um campo científico; produzir indicadores baseados em contagem de publicações e patente, para avaliação e planejamento das atividades de pesquisa científica e tecnológica, como também analisar o contexto sócio-histórico da produção da atividade científica (SILVA; HAYASHI; HAYASHI, 2011).

Nessa pesquisa seguimos os procedimentos metodológicos da análise bibliométrica utilizados por Hayashi et al. (2008) já aplicados nas pesquisas de Zauith, Ogata e Hayashi (2001) e Zauith e Hayashi (2011a; 2011b). A coleta de dados foi realizada em dezembro de 2012, no Banco de Teses e Dissertações da Capes e no Caderno de Indicadores da Capes de Programas de Pós-Graduação vinculados a grande área Multidisciplinar e área em Ensino.

Para a coleta de dados no Banco de Teses da Capes foram utilizadas as seguintes expressões de busca: "Educação CTS", "Ensino CTS", "Ensino de Ciências Paulo Freire", Os dados foram registrados em um protocolo elaborado com o software MS Excel, contendo os seguintes parâmetros: gênero e vinculação dos autores e orientadores; ano de defesa, programas de pós-graduação e instituições; linhas de pesquisa; temáticas abordadas e resumos. Posteriormente os dados coletados foram transferidos ao software de análise bibliométrica VantagePoint ${ }^{\circledR}$. Em seguida, para categorização dos autores e dos temas abordados, foram lidos os resumos dos trabalhos selecionados, bem como o texto completo, quando disponíveis on-line, para certificação dos critérios de inclusão na pesquisa com referência à pedagogia freireana.

A coleta de dados nos Cadernos de Indicadores da Capes referentes ao triênio 20072009 dos cursos recomendados pertencentes a grande área Multidisciplinar e área de avaliação Ensino. Foram consultados os documentos anuais desse triênio referentes às disciplinas oferecidas (DI). A busca utilizou o prefixo "freir" como sinalizador da presença do referencial freireano nos títulos, ementas e nas bibliografias dessas disciplinas.

Os dados coletados foram inseridos em duas planilhas MS Excel. Na primeira constam as informações: instituição de ensino, programa de pós-graduação, nome da disciplina, docente (s), ementa e ano de oferta. E na segunda planilha foram inseridas informações sobre a instituição de ensino, o nome da disciplina, as referências utilizadas e o ano de oferta da disciplina. Para o presente artigo foi realizado um recorte na totalidade dos dados coletados dessa segunda planilha, sendo selecionados os dados da UFSC, UnB e USP. A escolha dessas instituições deve-se ao fato de que são as que mais concentram trabalhos com o enfoque freireano. É preciso deixar claro que os resultados dessa amostra não podem ser generalizados, visto que a análise está limitada aos dados coletados disponíveis para consulta nos Cadernos de Indicadores, uma vez que Programas de Pós-Graduação que estão em fase de homologação esses documentos não estão disponibilizados. Por sua vez, a busca pelas teses e dissertações está atrelada às universidades em que foram defendidas e nem todas disponibilizam integralmente os textos em seus Bancos Digitais de Teses e Dissertações. 


\section{A presença da produção acadêmica de Paulo Freire na Educação CTS e no Ensino de Ciências}

Na primeira etapa da coleta de teses e dissertações o Banco de Teses da Capes foi interrogado utilizando com os termos de busca: "Educação CTS", "Ensino CTS", "Ensino de Ciências Paulo Freire", resultando em 306 trabalhos. Posteriormente foi realizada a triagem para eliminar repetições, chegando a 200 trabalhos. Na etapa seguinte foram localizados 125 trabalhos com texto completo na Biblioteca Digital Brasileira de Teses e Dissertações do Instituto Brasileiro de Informação em Ciência, do Ministério da Ciência, Tecnologia e Inovação (BDTD/IBICT/MCT), e nas bibliotecas digitai dos Programas de Pós-Graduação.

A terceira etapa consistiu em verificar a presença da perspectiva teórica de Paulo Freire nos trabalhos. A busca nos resumos pela palavra "Freire" resultou em 43 trabalhos, os quais compõem o corpus da pesquisa. Destes, 26 são de mestrado, 8 de mestrado profissional e 9 de doutorado e foram elaborados entre 2001 e 2010, conforme apontam os dados da Tabela 1

Tabela 1 - Distribuiçãa das teses e dissertações acadêmicas e profissionalizantes

\begin{tabular}{|c|c|c|c|c|}
\hline Ano & Doutorado & Mestrado & $\begin{array}{c}\text { Mestrado } \\
\text { Profissionalizante }\end{array}$ & Total \\
\hline 2001 & 1 & 0 & 0 & 1 \\
\hline 2002 & 1 & 1 & 0 & 2 \\
\hline 2004 & 1 & 0 & 0 & 1 \\
\hline 2005 & 0 & 1 & 0 & 1 \\
\hline 2006 & 0 & 5 & 0 & 5 \\
\hline 2007 & 2 & 4 & 2 & 9 \\
\hline 2008 & 1 & 8 & 2 & 11 \\
\hline 2009 & 2 & 6 & 1 & 3 \\
\hline 2010 & 1 & 1 & $\mathbf{8}$ & $\mathbf{4 3}$ \\
\hline Total & $\mathbf{9}$ & $\mathbf{2 6}$ & 2 & \\
\hline
\end{tabular}

Na Tabela 2 é possível observar que as instituições de ensino que mais concentram os trabalhos são a Universidade Federal de Santa Catarina (8), Universidade de Brasília (7) e Universidade de São Paulo (6). Localizadas em sua maioria na região Sudeste (18), Sul (14), Centro-Oeste (7) e Nordeste (4), são instituições com vinculações administrativas federais (27), estaduais (9) e particulares (7). 
Tabela 2: Distribuição dos trabalhos nas instituições de ensino

\begin{tabular}{|l|c|}
\hline \multicolumn{1}{|c|}{ IES } & Trabalhos \\
\hline UFSC & 8 \\
\hline UnB & 7 \\
\hline USP & 10 \\
\hline UFRPE; UFSM; PUC-SP; PUC-MG; UFPI (2 trabalhos cada) & 12 \\
\hline $\begin{array}{l}\text { Centro Federal de Educação Tecnológico de Minas Gerais; UFRGS; Centro } \\
\text { Universitário Salesiano de São Paulo; PUC-PR; UNIJUI; UNISANTOS; } \\
\begin{array}{l}\text { UNICAMP; UEMG; UNIMONTES; UNESP/Bauru; UFPel; UFSCar (1 trabalho } \\
\text { cada) }\end{array}\end{array}$ & $\mathbf{4 3}$ \\
\hline \multicolumn{2}{|c|}{ Total } \\
\hline \multicolumn{2}{|c|}{ Elaboração das Autoras. Fonte: Banco de Teses da CAPES }
\end{tabular}

Além disso, verificou-se que esses 43 trabalhos estão concentrados em 14 Programas de Pós-Graduação, vinculados a seis áreas de conhecimento: Educação; Ensino, Interdisciplinar, Ciências Ambientais, Enfermagem e Engenharia Elétrica, conforme apontam os dados da Tabela 3.

Tabela 3: Distribuição de trabalhos por Programas de Pós-Graduação.

\begin{tabular}{|c|c|c|}
\hline GRANDES ÁREAS & ÁREAS/PROGRAMAS & TOTAL \\
\hline \multirow{5}{*}{ CIENCIAS HUMANAS } & EDUCAÇÃO & \\
\hline & Educação & 8 \\
\hline & 2 Educação (Currículo) & 9 \\
\hline & 3 Educação nas Ciências & 1 \\
\hline & 4 Educação Tecnológica & 1 \\
\hline \multirow{11}{*}{ MULTIDISCIPLINAR } & ENSINO & \\
\hline & $\begin{array}{ll}5 & \text { Ensino de Ciências } \\
\end{array}$ & 6 \\
\hline & 6 Ensino das Ciências & 2 \\
\hline & $\begin{array}{ll}7 & \begin{array}{l}\text { Ensino de Ciências (Física, Química e } \\
\text { Biologia) }\end{array} \\
\end{array}$ & 2 \\
\hline & $8 \quad$ Ensino & 2 \\
\hline & 9 Educação para a Ciência & 1 \\
\hline & 10 Educação Científica e Tecnológica & 7 \\
\hline & $\begin{array}{l}\text { INTERDISCIPLINAR } \\
\end{array}$ & \\
\hline & 11 Desenvolvimento Social & 1 \\
\hline & $\begin{array}{l}\text { CIÊNCIAS AMBIENTAIS } \\
\end{array}$ & \\
\hline & 12 Desenvolvimento Sustentável & 1 \\
\hline \multirow{2}{*}{ CIÊNCIAS DA SAÚDE } & $\begin{array}{l}\text { ENFERMAGEM } \\
\end{array}$ & \\
\hline & 13 Enfermagem Psiquiátrica & 1 \\
\hline \multirow{3}{*}{ ENGENHARIAS } & $\begin{array}{l}\text { ENGENHARIA ELÉTRICA } \\
\end{array}$ & \\
\hline & 14 Engenharia Elétrica & 1 \\
\hline & TOTAL & 43 \\
\hline
\end{tabular}

Elaboração das Autoras. Fonte: Banco de Teses da CAPES

Quando se analisou o apoio de agências de fomento às pesquisas verificou-se que em sua maioria os trabalhos não possuem financiamento (25, ou seja, 58,14\%), sendo que 13 $(30,23 \%)$ foram apoiados pela Capes e os cinco $(11,63 \%)$ restantes pelo CNPq, Convênio 
Interinstitucional Entidade Internacional Moçambique e Secretaria da Educação do Estado de São Paulo.

As palavras-chave mais utilizadas pelos autores para representar o conteúdo desses trabalhos totalizaram 92. Ao examinar essas palavras-chaves podemos estabelecer uma relação com os temas abordados nesses trabalhos, conforme exibido na Tabela 4.

Tabela 4- Temas abordados nas pesquisas

\begin{tabular}{|l|c|}
\hline \multicolumn{1}{|c|}{ Temas } & $\begin{array}{c}\text { Palavras- } \\
\text { chave }\end{array}$ \\
\hline Ensino de Ciências (5); Ensino de Física (2); Física (3); Biologia (1) & 11 \\
\hline $\begin{array}{l}\text { Divulgação científica (3); Educação científica (1); Cultura Científica (1); Letramento } \\
\text { científico e tecnológico (1) }\end{array}$ & 6 \\
\hline Abordagem CTS & 5 \\
\hline Educação ambiental (4); Crise ambiental (1) & 5 \\
\hline Problematização (2); Atividades problematizadas (3); & 5 \\
\hline Total & $\mathbf{3 2}$ \\
\hline
\end{tabular}

Também foi possível identificar no corpus analisado os professores que mais orientaram trabalhos, conforme discriminado na Tabela 5. A UFSC comparece com os docentes Décio Auler e Demetrio Delizoicov Neto, ambos com 3 orientações cada, seguidos daqueles com 2 orientações: Cássio Costa Laranjeiras e Gerson de Souza Mól da UNB, Irlan von Linsingen da UFSC, José Augusto de Carvalho Mendes Sobrinho da UFPI, Maria Marly de Oliveira da UFRPE, Maria Regina Dubeux Kawamura e Yassuko Hosoume da USP. Os demais docentes orientaram apenas um trabalho.

Tabela 5 - Orientadores dos trabalhos

\begin{tabular}{|c|c|}
\hline Orientadores & Trabalhos \\
\hline Décio Auler; Demetrio Delizoicov Neto (3 trabalhos cada) & 6 \\
\hline $\begin{array}{l}\text { Cássio Costa Laranjeiras; Gerson de Souza Mól; Irlan von Linsingen; José Augusto } \\
\text { de Carvalho Mendes Sobrinho; Maria Marly de Oliveira; Maria Regina Dubeux } \\
\text { Kawamura; Yassuko Hosoume ( } 2 \text { trabalhos cada) }\end{array}$ & 14 \\
\hline $\begin{array}{l}\text { Adelson Fernandes Moreira; Alice Helena Campos Pierson; Carlos Alberto } \\
\text { Marques; Casimiro M. Marques Balsa; Eduardo Fleury Mortimer; Fernando José } \\
\text { de Almeida; Gomercindo Ghiggi; João Marcos Travassos Romano; João Zanetic; } \\
\text { Joice de Aguiar Baptista; Lizete Maria Orquiza de Carvalho; Maria Lourdes Gisi; } \\
\text { Maria Lucia Vital dos Santos Abib; Marlene Ribeiro; Mauricio Pietrocola Pinto de } \\
\text { Oliveira; Mere Abramowicz; Milton Antonio Auth; Roberto dos Santos Bartholo } \\
\text { Júnior; Sonia Maria Villela Bueno; Sueli Maria Pessagno Caro; Sueli Mazzilli; } \\
\text { Suzani Cassiani de Souza; Wildson Luiz Pereira dos Santos (1 trabalho cada). }\end{array}$ & 23 \\
\hline Total & 43 \\
\hline
\end{tabular}

Esses achados confirmam a pesquisa anterior de Zauith, Ogata e Hayashi (2011) que indentificou o núcleo conceitual de pesquisadores ibero-americanos da Educação CTS composto por: Décio Auler, Walter Antonio Bazzo, Demétrio Delizoicov, Irlan von Linsingen, Wildson dos Santos, Arden Zylbersztajn. Segundo a pesquisa, a UFSC, por meio 
do Programa de Pós-Graduação Educação Científica e Tecnológica, foi responsável pelo maior número de trabalhos de Educação CTS entre 2004 e 2008.

Por sua vez, os autores das 43 dissertações e teses totalizaram 41, conforme mostra o Quadro 3 que relaciona esses autores.

Quadro 3 - Autores dos 43 trabalhos

\begin{tabular}{|l|l|}
\hline \multicolumn{2}{|c|}{ Autores } \\
\hline Ailson Vasconcelos da Cunha & Maria Stela da Costa Gondim \\
\hline Antonia Marcia Duarte Queiroz & Marinalva Luiz de Oliveira \\
\hline Carlos Gomes & Marta Maria Azevedo Queiroz \\
\hline Claudia Battestin & Mônica Marques de Paula \\
\hline Cleusa Helena Guaita Peralta & Neuton Alves de Araujo \\
\hline Cristiane Muenchen & Nília Oliveira Santos \\
\hline Cristiano Cordeiro Cruz & Patricia Amaral \\
\hline Eliane Mendes Guimarães & Paulo Henrique de Souza \\
\hline Fabrícia Amorim & Renata Alves Ribeiro \\
\hline Fernando Eduardo Mesadri & Rita de Cássia Bortoletto Santos \\
\hline Fernando José Fernandes Gonçalves & Roseline Beatriz Strieder \\
\hline Frederico Vasconcellos Costa & Sandra Gonçalves Coimbra \\
\hline Gisnaldo Amorim Pinto & Sandra Hunsche \\
\hline Gustavo Henrique Moraes & Simoni Tormöhlen Gehlen \\
\hline Jó Antonio Capece & Suzana de Souza Guedes \\
\hline Kely Cristina Pereira & Tatiana Galieta Nacimento \\
\hline Leonardo Augusto Gonçalves Ferreira & Tomás de Aquino Silveira \\
\hline Lourival Gomes da Silva Filho & Wagdo da Silva Martins \\
\hline Marcia Regina Carletto & Wallesandra Araújo Silva \\
\hline Marcia Soares Forgiarini & Wildson Luiz Pereira dos Santos \\
\hline Maria Nizete de Azevedo & \\
\hline
\end{tabular}

Elaboração das Autoras. Fonte: Banco de Teses da CAPES

$\mathrm{Na}$ impossibilidade de analisar nesse artigo o conteúdo de todos os 43 trabalhos foram selecionados alguns que compuseram uma pequena amostra dessa totalidade e que foi pautada pela tentativa de apresentar pelo menos um de cada uma das 14 áreas de conhecimento conforme dados da Tabela 3.

É interessante mencionar que entre esses autores, apenas duas realizaram mestrado e doutorado (Cristiane Muenchen e Simoni Tormöhlen Gehlen), sendo digno de nota que o orientador de ambas no doutorado foi Demétrio Delizoicov Neto (UFSC) enquanto que Décio Auler (UFSC) orientou a primeira no mestrado e Milton Antonio Auth (UNIJUÍ) a segunda.

No mestrado, realizado na área de Educação, Muenchen (2006) analisou os desafios enfrentados no âmbito de intervenções curriculares que buscam enfocar interações entre Ciência-Tecnologia-Sociedade, mediante a abordagem de temáticas contemporâneas, marcadas pela componente científico-tecnológica. $\mathrm{Na}$ visão da autora, tais encaminhamentos curriculares estão balizados por uma aproximação entre pressupostos do educador brasileiro Paulo Freire e referenciais ligados ao denominado movimento CTS. Assim, para que ocorre uma leitura crítica da realidade, dimensão fundamental em Freire, entende-se que é, cada vez mais, necessária uma compreensão crítica das interações entre CTS, considerando que a dinâmica social contemporânea está fortemente condicionada pela 
ciência e tecnologia. Como síntese dos resultados da investigação, foram definidas e discutidas quatro categorias, as quais constituem desafios a serem enfrentados: a) superação do reducionismo metodológico, ou seja, ao professor atribui-se o papel de "vencer programas"; b) o trabalho interdisciplinar; c) suposta resistência dos alunos à abordagem temática e d) desenvolvimento de temas polêmicos que envolvem conflitos/contradições locais.

No doutorado, realizado na área de Educação Científica e Tecnológica, Muenchen (2010) investiga práticas pedagógicas de professores de Ciências da região de Santa Maria/RS que usam os denominados Três Momentos Pedagógicos (3MP). Dentre os resultados, destaca-se que o contexto da proposição dos 3MP é decorrência da transposição da concepção de Paulo Freire para a educação escolar e teve como referência três projetos: um desenvolvido na África e dois no Brasil.

Por sua vez, a dissertação de Gehlen (2006), na área de Educação nas Ciências, buscou desenvolver e implementar duas propostas curriculares para o Ensino de Ciências balizadas, respectivamente, pelos pressupostos do educador brasileiro Paulo Freire e pela teoria do russo Lev S. Vigotski. Dentre os resultados obtidos a autora aponta que aspectos como a problematização presente na concepção educacional de Freire e a questão da significação conceitual baseada em Vigotski, podem enriquecer ambas as propostas e potencializam organizações curriculares para o Ensino de Ciências. A autora também obteve indicativos teórico-empíricos de que as concepções desses autores se complementam e caracterizam os temas e situações como significativas, tanto para o professor quanto para o aluno.

No doutorado, Gehlen (2009), na área de Educação Científica e Tecnológica, a autora investiga a noção de problema na obra de Vygotsky e sua função no processo de ensino-aprendizagem em Ciências. A partir de interlocuções entre Freire e Vygotsky, a pesquisa buscou contribuir com reflexões epistemológicas e pedagógicas sobre o papel do problema no processo de ensino-aprendizagem. Dentre os resultados, destaca-se que a noção de problema na obra de Vygotsky está diretamente vinculada ao processo de humanização e, numa dimensão epistemológica, está relacionada com o objeto do conhecimento. Isto é, o problema assume um papel na gênese da produção e apropriação de signos, assim como é o mediador nas relações entre sujeito e objeto do conhecimento. Ao final a autora verifica que há complementaridade entre a Situação de Estudo e a Abordagem Temática Freireana, o que contribui na estruturação de práticas-pedagógicas para o Ensino de Ciências.

Também é válido mencionar que Wildson Luiz Pereira dos Santos, foi orientado no doutorado por Eduardo Fleury Mortimer (UEMG) e posteriormente foi orientador da dissertação de Wagdo da Silva Martins (UnB).

No doutorado realizado na área de Educação Santos (2002) analisa o processo pedagógico da abordagem de aspectos sócio-científicos (ASC) para o currículo e para o processo de formação de professores em relação aos objetivos de formação para a cidadania. $\mathrm{Na}$ fundamentação teórica da pesquisa o autor lança mão da proposta de educação humanística de Paulo Freire. Ao final a pesquisa conclui que os ASC potencializam interações dialógicas, possibilitam a introdução de atitudes e valores e podem ser configurados como elementos constitutivos dos currículos.

Por sua vez, no mestrado profissionalizante na área de Educação, Wagdo da Silva Martins (2007) propõe-se a elaborar um módulo de ensino de Química que buscasse atender 
as necessidades da educação de jovens e adultos (EJA) e toma os princípios educacionais de Paulo Freire como referência para produzir um módulo de ensino que parte "Tinta e Solventes" considerando-o como um tema gerador freireano, para desenvolver conceitos básicos de substâncias, suas propriedades e interações. Ao final a proposta de material recebeu avaliação positiva dos professores e o autor conclui que ela apresenta potencial de produzir impactos positivos no ensino de Química no EJA

A tese de doutorado de Jó Antonio Capece (2001) foi orientada por Fernando José de Almeida, na PUC-SP, na área de Educação (Currículo). O autor procura introduzir um olhar crítico e sugerir uma nova perspectiva para o processo de ensino e aprendizagem em Moçambique, mormente no que concerne à disciplina de Ciências Naturais. Para isso, toma como referência, entre outras, as obras de Paulo Freire: "Pedagogia do oprimido". A pesquisa assumiu o resgate dos saberes locais para o currículo oficial, por permitir a apropriação dos aspectos da vida cotidiana das comunidades. Tratou-se, portanto, de questionar e problematizar o processo de ensino e aprendizagem moçambicano, uma vez que se tomou como pressuposto que até então os currículos se mostravam desvinculados da realidade cultural do aluno.

Por sua vez, a tese de Tatiana Galieta Nascimento (2008), orientada por Suzani Cassiani de Souza, na UFSC, na área de Educação Científica e Tecnológica, buscou investigar as leituras feitas por licenciandos de textos de divulgação científica desenvolvidas na disciplina Prática de Ensino das Ciências Biológicas. A autora defende a tese de que textos de divulgação científica podem propiciar leituras críticas das relações entre ciência, tecnologia e sociedade em sala de aula desde que o professor esteja alinhado a uma concepção educacional progressista crítica. A pesquisa adotou o referencial teórico metodológico da Análise do Discurso de linha francesa e a filosofia de Paulo Freire para analisar aspectos como: as condições de produção das aulas, os modos de leitura e os gestos de interpretação, as reelaborações discursivas (tanto as escritas como as orais), imagens, usos e funções dos textos de divulgação científica. Ao final, a autora aponta a necessidade de novos estudos teóricos que discutam, sob o ponto de vista da área de educação em ciências, o papel da divulgação científica no ensino formal, focalizando inclusive o papel que o texto de divulgação exerceria na introdução de temas da ciência contemporânea nas aulas de ciências como uma forma de atualização dos conteúdos no ensino de ciências.

A dissertação de mestrado de Roseline Beatriz Strieder (2008), orientada por Maria Regina Dubeux Kawamura, na USP, na área de Ensino de Ciências, investiga, tanto em âmbito teórico quanto prático, os elementos de articulação entre a abordagem CTS e a perspectiva freireana de educação. Essa articulação, de acordo com a autora, implicou em redesenhar alguns elementos, etapas e procedimentos para a intervenção, tomando como ponto de partida a investigação temática. A autora constatou que essa visão promove um novo nível de conhecimento da realidade, além de mudanças de percepção, por parte dos alunos, sobre o sentido da escola, do próprio conhecimento e da questão em estudo.

Em 2005, a dissertação de mestrado de Marinalva Luiz de Oliveira, orientada por Maria Marly de Oliveira na UFRPE, na área de Ensino das Ciências, busca compreender o trabalho pedagógico dos professores do ensino fundamental sobre a educação ambiental. A fundamentação teórica parte da reconstrução da concepção ontológica do trabalho humano e sua aproximação com a teoria do agir comunicativo, em consonância com a teoria pedagógica de Paulo Freire. Os resultados revelaram que o trabalho pedagógico dos 
professores com a educação ambiental depende de seus posicionamentos com relação à teoria pedagógica, podendo, eles assumirem o posicionamento bancário (informador, alienador e transmissor de conhecimentos) ou crítico e emancipatório (construtor e reconstrutor de conhecimento), mesmo que no momento do encontro pedagógico os professores sejam orientados pelo entendimento.

A dissertação de mestrado de Renata Alves Ribeiro (2007), defendida na área de Ensino de Ciências (Química, Física e Biologia) na USP, sob a orientação de Maria Regina Dubeux Kawamura, investigou as potencialidades atribuídas à divulgação científica nas pesquisas da área de ensino de Física, com o objetivo de sistematizá-las e articulá-las com uma concepção de educação fundamentada no pensamento de Paulo Freire. A autora conclui um quadro de diferentes vertentes da divulgação científica, articuladas por suas intenções é fruto das vertentes "leitura de mundo, mundo de leitura", "formação do espírito crítico", "contextualização e atualidade" e "olhar da sedução: encantamento e motivação". Ao mesmo tempo em que compõem potencialidades da divulgação, essas visões representam objetivos formativos integrados em uma visão sobre a ação de educar.

Tomás de Aquino Silveira (2008) defendeu dissertação de mestrado profissionalizante na PUC-SP, na área de Ensino, sob a orientação de Yassuko Hosoume. O autor apresenta uma proposta para a disciplina "Evolução das Ideias da Física" calcada na abordagem da História da Ciência, visando estimular o professor para a prática de reflexão sobre sua atividade profissional. Para isso recorre à pedagogia de Paulo Freire, com sua valorização da autonomia e na relação dialógica entre educador/educando; a escola soviética, com sua ênfase na relação entre palavra e pensamento. Ao final, a pesquisa verificou a aceitação da proposta da disciplina pelos alunos e professores.

Na UNESP/Bauru, a dissertação de Ailson Vasconcelos da Cunha (2008), na área de Educação para a ciência e orientada por Lizete Maria Orquiza de Carvalho, buscou inserir conteúdos de História, Filosofia e Sociologia da Ciência no Ensino de Ciências. Para isso explicita a sua concepção de educação embasada principalmente pela obra do educador Paulo Freire, ou seja, a concepção de educação dialógica-problematizadora na vertente emancipadora. Em seguida, o autor faz uma aproximação entre a concepção freireana de educação e o Ensino de Ciências a fim de estabelecer uma concepção de Ensino de Ciências, argumentando em favor de sua inseparabilidade com a Ciência no Ensino de Ciências. Conclui que a construção de enunciados sobre uma determinada experiência da Física a partir desse referencial teórico proporcionou aos alunos uma transformação da realidade.

Na Unimontes, a dissertação de mestrado de Antonia Marcia Duarte Queiroz (2009), sob a orientação de Casimiro Marques Balsa, na área de Desenvolvimento Social, se propôs a analisar algumas das concepções da Extensão Universitária dessa instituição de ensino superior. A autora investigou a relação ensino, pesquisa e extensão, e algumas concepções de extensão e transformações pelas quais a Unimontes passou no período em análise e a sua adequação (ou não) aos parâmetros e diretrizes nacionais. À luz de autores, como Paulo Freire, Boaventura de Souza Santos e Carlos Rodrigues Brandão, analisaram-se alguns princípios norteadores da Extensão Universitária. Ao final, a autora observou que essas concepções de extensão seguem perspectivas complexas, que se aproximam da extensão praticada nas universidades públicas brasileiras. 
A tese de doutorado de Eliane Mendes Guimarães (2004), defendida na UnB sob a orientação de Roberto dos Santos Bartholo Jr., na área de Desenvolvimento Sustentável, parte do pressuposto de que a abordagem da educação ambiental considera o ambiente em uma visão ampla incluindo o humano e as questões socioeconômicas. Nesse contexto, a teoria de Humberto Maturana apresenta um novo paradigma para pensar a Biologia, a Ciência e a Educação. Além disso, na visão da autora, tal teoria apresenta uma aproximação com as pedagogias dialógicas, tanto de Martin Buber como de Paulo Freire, dando um grande suporte para trabalhos com comunidades excluídas. Em vista disso, a autora apresenta a discussão da Teoria da Autopoiese aplicada ao trabalho educativo na cidade de Samambaia, no Distrito Federal, realizado em um projeto de extensão de ação contínua "Construindo Saúde e Cidadania" da Universidade de Brasília (UnB). Ao final, a autora conclui que s teorias de Maturana, Paulo Freire e Martin Buber, estão interligadas pela dialogicidade e puderam elucidar os trabalhos em Samambaia, considerando as dimensões humanas bio-psico-culturais entrelaçadas.

Cristiano Cordeiro Cruz (2002) defendeu dissertação de mestrado na Unicamp, na área de Engenharia Elétrica e foi orientado por João Marcos Travasso Romano. O autor objetivou discutir a formação acadêmica nos cursos superiores de Engenharia, particularmente, no curso de Engenharia Elétrica da Unicamp. A análise baseou-se nos princípios da formação humanista, considerada pelo autor como uma formação que visa lidar com o indivíduo completo, não se atendo ao meramente técnico. Para isso o autor recorre a algumas ideias de Paulo Freire e Josef Pieper, e das considerações centrais do campo Ciência, Tecnologia e Sociedade (CTS). Com base nesses pressupostos teóricos o autor chega à tríade: diálogo, comprometimento com o próximo e busca filosófica pela verdade. Em sua visão, essa concepção busca capacitar o ser humano para "ser mais", e só pode ocorrer em uma formação que proveja uma visão crítica e holística da realidade.

A dissertação de mestrado de Kely Cristina Pereira (2007) foi defendida na USP/Ribeirão Preto, na área de Enfermagem Psiquiátrica e orientada por Sonia Maria Villela Bueno. A autora pesquisou a sexualidade na adolescência, objetivando levantar as amplas questões que a envolvem e a trabalhar com adolescentes escolares a educação preventiva, mediante a implementação de um Programa Educativo, numa perspectiva participativa, problematizadora e reflexiva. Os referenciais teórico-metodológicos foram buscados em Paulo Freire, no que tange à problematização, humanização, otimização da vida e visão totalizadora do ser humano. O Programa Educativo construído foi subsidiado com uma concepção crítica e reflexiva, com vistas à práxis comprometida com a educação libertadora, favorecendo atitudes responsáveis e efetivas na edificação de uma identidade consciente e autônoma, à luz da qualidade de vida.

\subsection{A presença de Paulo Freire em disciplinas de Programas de Pós-graduação em Ensino de Ciências}

A busca nos Cadernos de Indicadores da Capes para identificar as disciplinas que utilizaram o referencial teórico freireano nos Programas da área de Ensino, identificou a existência de 57 disciplinas, distribuídas entre 22 instituições conforme mostram os dados do Quadro 4 
Quadro 4 - Disciplinas que utilizam o referencial teórico freireano

\begin{tabular}{|c|c|}
\hline Instituições & Disciplinas/Ano de oferta \\
\hline $\begin{array}{l}\text { Universidade de São Paulo } \\
\text { (USP) }\end{array}$ & $\begin{array}{l}\text { Ambientes de aprendizagem cooperativa apoiados em tecnologia } \\
\text { Aspectos teórico-metodológicos da abordagem piagetiana } \\
\text { Economia solidária e educação - a construção de uma alternativa } \\
\text { Educação e sociedade no Brasil Contemporâneo } \\
\text { Filosofia da Educação: uma análise filosófica do discurso } \\
\text { Graus de letramento/literacia e a construção de conhecimento } \\
\text { Mudança educacional: inovação e reforma } \\
\text { Perspectivas atuais da educação } \\
\text { Avaliação de programas e projetos em educação } \\
\text { Financiamento educacional e gestão democrática do ensino público: } \\
\text { concepções, processos e implicações de políticas educacionais recentes }\end{array}$ \\
\hline $\begin{array}{l}\text { Universidade Federal do Rio de } \\
\text { Janeiro (UFRJ) }\end{array}$ & $\begin{array}{l}\text { Comunicação e Educação em Ciências e Saúde } \\
\text { Educação em Ciências e Saúde 2: tendências } \\
\text { Educação, Tecnologia e Sociedade } \\
\text { Planejamento curricular e de ensino na área da Saúde } \\
\text { Tópicos Especiais em Educação em Saúde } \\
\text { Educação em ciências e saúde I - fundamentos } \\
\text { Ciências sociais, comunicação e saúde }\end{array}$ \\
\hline $\begin{array}{l}\text { Universidade Estadual de } \\
\text { Maringá (UEM) }\end{array}$ & $\begin{array}{l}\text { A questão das mídias na educação científica e tecnológica } \\
\text { Concepção e desenvolvimento curricular } \\
\text { Didática da Geografia } \\
\text { Educação e ação docente } \\
\text { Educação Intercultural } \\
\text { Tópicos complementares de geografia }\end{array}$ \\
\hline $\begin{array}{l}\text { Universidade Federal do Rio } \\
\text { Grande do Sul (UFRGS) }\end{array}$ & $\begin{array}{l}\text { Processos de desenvolvimento humano e a aprendizagem de ciências } \\
\text { em contexto escolar } \\
\text { SEM: Grupo Mirar: Formação de professores de Ciências articulado ao } \\
\text { desenvolvimento curricular } \\
\text { Teorias curriculares: reformas e mudanças na educação em Ciências } \\
\text { Tópicos especiais: Unidade de aprendizagem: abordagens da ciência, } \\
\text { tecnologia e sociedade }\end{array}$ \\
\hline $\begin{array}{l}\text { Fundação Oswaldo Cruz } \\
\text { (FIOCRUZ) }\end{array}$ & $\begin{array}{l}\text { Aprendizagem e avaliação } \\
\text { Metodologia de ensino e avaliação } \\
\text { Popularização científica à distância }\end{array}$ \\
\hline $\begin{array}{l}\text { Pontifícia Universidade Católica } \\
\text { do Rio Grande do Sul (PUC-RS) }\end{array}$ & $\begin{array}{l}\text { SAE: procedimentos didático-pedagógicos e relações interpessoais } \\
\text { Princípios da educação pela pesquisa } \\
\text { Metodologia do ensino superior }\end{array}$ \\
\hline $\begin{array}{l}\text { Universidade Federal de São } \\
\text { Paulo (UNIFESP) }\end{array}$ & $\begin{array}{l}\text { Aprendizagem de adultos } \\
\text { Ler e Escrever: instrumentos de produção e disseminação do } \\
\text { conhecimento }\end{array}$ \\
\hline $\begin{array}{l}\text { Pontifícia Universidade Católica } \\
\text { de Minas Gerais (PUC-MG) }\end{array}$ & $\begin{array}{l}\text { Educação, sociedade e construção identidade do professor } \\
\text { Ensino de Física na educação básica }\end{array}$ \\
\hline $\begin{array}{l}\text { Universidade Federal de Mato } \\
\text { Grosso do Sul (UFMS) }\end{array}$ & $\begin{array}{l}\text { Formação do professor de Ciências } \\
\text { Metodologia da pesquisa em Ensino de Ciências I }\end{array}$ \\
\hline Universidade de Brasília (UnB) & $\begin{array}{l}\text { Educação científica, tecnológica e ambiental } \\
\text { Educação ambiental no ensino de Ciências }\end{array}$ \\
\hline $\begin{array}{l}\text { Universidade Federal Rural de } \\
\text { Pernambuco (UFRPE) }\end{array}$ & $\begin{array}{l}\text { Metodologia do ensino superior } \\
\text { Teorias da aprendizagem }\end{array}$ \\
\hline
\end{tabular}




\begin{tabular}{|c|l|}
\hline $\begin{array}{c}\text { Universidade Estadual Paulista } \\
\text { (UNESP/Rio Claro) }\end{array}$ & $\begin{array}{l}\text { Educação etnomatemática: história, cultura e prática pedagógica } \\
\text { TEEM: cotidiano e cultura escolar }\end{array}$ \\
\hline $\begin{array}{c}\text { Universidade Federal de Goiás } \\
\text { (UFG) }\end{array}$ & $\begin{array}{l}\text { Teorias de aprendizagem e ensino } \\
\text { A interdisciplinaridade e a transversalidade no ensino de Ciências }\end{array}$ \\
\hline $\begin{array}{c}\text { Universidade Federal de Santa } \\
\text { Catarina (UFSC) }\end{array}$ & $\begin{array}{l}\text { Prática freireana em ensino de ciências na educação escolar } \\
\text { Educação mediada por tecnologia }\end{array}$ \\
\hline $\begin{array}{c}\text { Universidade Técnica Federal do } \\
\text { Paraná (UTFPR) }\end{array}$ & Tópicos em ensino de Ciências nas séries iniciais \\
\hline $\begin{array}{c}\text { Universidade Estadual Paulista } \\
\text { (UNESP/Bauru) }\end{array}$ & Comunicação e saúde \\
\hline $\begin{array}{c}\text { Universidade Severino Sombra } \\
\text { (USS) }\end{array}$ & Formação de professores: tendências e perspectivas de pesquisa \\
\hline $\begin{array}{c}\text { Universidade Federal de Ouro } \\
\text { Preto (UFOP) }\end{array}$ & A educação matemática enquanto campo do saber \\
\hline $\begin{array}{c}\text { Universidade Estadual de } \\
\text { Campinas (Unicamp) }\end{array}$ & Opções de trabalho pedagógico em geociências \\
\hline $\begin{array}{c}\text { Universidade Federal do Rio } \\
\text { Grande do Norte (UFRN) }\end{array}$ & Tendências atuais do ensino de química \\
\hline $\begin{array}{c}\text { Universidade Federal do Ceará } \\
\text { (UFC) }\end{array}$ & Teorias da Educação \\
\hline $\begin{array}{c}\text { Centro Universitário Plínio Leite } \\
\text { de Limeira-SP (UNIPLI) }\end{array}$ & Ensino, cultura e sociedade em saúde e ambiente \\
\hline
\end{tabular}
Elaboração das autoras. Fonte: Cadernos de Indicadores Capes.

De acordo com Menezes (1996), na década de 1970 formou-se um grupo de físicos composto por João Zanetic, Amélia Império Hamburger, Demétrio Delizoicov e José André Angotti que tinha como objetivo transformar o ensino escolar da física, tradicionalmente formal e propedêutico a partir de uma metodologia de inspiração freireana. Deste grupo, Zanetic, Delizoicov e Angotti continuam trabalhando com Paulo Freire como orientadores de trabalhos. Delizoicov e Angotti ministraram as disciplinas "Prática freireana em Ensino de Ciências na Educação Escolar" e "Educação mediada por tecnologia", respectivamente na pós-graduação em Educação Científica e Tecnológica da UFSC.

No Quadro 5 é possível verificar as disciplinas ministradas nos Programas de PósGraduação da UFSC, UnB e USP no triênio 2007-2009, e que abordam em seu conteúdo o referencial freireano.

Quadro 5- Disciplinas ministradas em programas de pós-graduação entre 2007-2009

\begin{tabular}{|c|c|c|c|}
\hline IES & PPG & Disciplinas & Docente (s) \\
\hline \multirow{2}{*}{ UFSC } & \multirow{2}{*}{$\begin{array}{l}\text { Educação } \\
\text { Científica e } \\
\text { Tecnológica }\end{array}$} & Educação mediada por tecnologia & $\begin{array}{l}\text { José André Peres } \\
\text { Angotti }\end{array}$ \\
\hline & & $\begin{array}{l}\text { Prática freireana em ensino de Ciências na } \\
\text { educação escolar }\end{array}$ & $\begin{array}{l}\text { Demetrio Delizoicov } \\
\text { Neto }\end{array}$ \\
\hline \multirow[b]{2}{*}{ UnB } & \multirow{2}{*}{$\begin{array}{l}\text { Ensino de } \\
\text { Ciências }\end{array}$} & Educação cientifica tecnológica e ambiental & não consta \\
\hline & & Educação ambiental no Ensino de Ciências & $\begin{array}{l}\text { Lenise Aparecida } \\
\text { Martins Garcia }\end{array}$ \\
\hline \multirow{2}{*}{ USP } & \multirow{2}{*}{$\begin{array}{c}\text { Ensino de } \\
\text { Ciências } \\
\text { (modalidades }\end{array}$} & $\begin{array}{l}\text { Aspectos teórico-metodológicos da abordagem } \\
\text { piagetiana e a prática pedagógica escolar }\end{array}$ & não consta \\
\hline & & Economia solidária e educação - a construção & não consta \\
\hline
\end{tabular}




\begin{tabular}{|c|c|c|}
\hline \multirow{9}{*}{$\begin{array}{l}\text { Física, Química e } \\
\text { Biologia) }\end{array}$} & de uma alternativa & \\
\hline & Educação e sociedade no Brasil contemporâneo & Celso de Rui Beisiegel \\
\hline & $\begin{array}{l}\text { Graus de Letramento/Literacia e a construção } \\
\text { de conhecimento }\end{array}$ & $\begin{array}{c}\text { Idmea Semeghini } \\
\text { Prospero Machado } \\
\text { Siqueira }\end{array}$ \\
\hline & Mudança educacional: inovação e reforma & não consta \\
\hline & Perspectivas atuais da educação & Moacir Gadotti \\
\hline & $\begin{array}{l}\text { Ambientes de aprendizagem cooperativa } \\
\text { apoiados em tecnologia }\end{array}$ & $\begin{array}{l}\text { Stela Conceição } \\
\text { Bertholo Piconez }\end{array}$ \\
\hline & $\begin{array}{c}\text { Avaliação de programas e projetos em } \\
\text { educação }\end{array}$ & $\begin{array}{c}\text { Romualdo Luiz Portela } \\
\text { de Oliveira }\end{array}$ \\
\hline & $\begin{array}{l}\text { Filosofia da educação: uma análise filosófica do } \\
\text { discurso }\end{array}$ & não consta \\
\hline & $\begin{array}{l}\text { Gestão democrática do ensino público: } \\
\text { concepções, processos e implicações }\end{array}$ & $\begin{array}{l}\text { Rubens Barbosa de } \\
\text { Camargo }\end{array}$ \\
\hline
\end{tabular}

Elaboração das autoras. Fonte: Cadernos de Indicadores da Capes.

Merece destaque no Quadro 5 a presença de Moacir Gadotti, educador e parceiro de Paulo Freire, que ministrou a disciplina "Perspectivas Atuais da Educação", no programa Ensino de Ciências (modalidades Física, Química e Biologia) da USP. Dentre seus livros, Gadotti publicou em 1986 em conjunto com Paulo Freire e Sergio Guimarães o livro Pedagogia: diálogo e conflito (GADOTTI; FREIRE; GUIMARÃES, 1995) e em 1996, Paulo Freire: uma biobibliografia (GADOTTI, 1996).

O Quadro 6 a seguir relaciona as 12 obras de Paulo Freire e as nove de outros autores indicadas nessas disciplinas.

Quadro 6 - Indicações bibliográficas de e sobre Paulo Freire

\begin{tabular}{|c|l|c|}
\hline Ano & \multicolumn{1}{|c|}{ Tese, Livros e Artigo de Paulo Freire } & $\begin{array}{c}\text { Indicações } \\
\text { bibliográficas }\end{array}$ \\
\hline 1959 & Educação e sociedade brasileira (tese) & 1 \\
\hline 1968 & Educação como prática da liberdade & 2 \\
\hline 1979 a & Conscientização: uma introdução ao pensamento de Paulo Freire & 1 \\
\hline $1979 b$ & Educação e mudança & 2 \\
\hline 1981 & Ação cultural para a liberdade e outros escritos & 2 \\
\hline 1983 a & Pedagogia do Oprimido & 4 \\
\hline $1983 b$ & Extensão ou comunicação? & 2 \\
\hline 1991 & A educação na cidade & 1 \\
\hline 1992 & $\begin{array}{l}\text { Pedagogia da esperança: um reencontro com a Pedagogia do } \\
\text { Oprimido }\end{array}$ & 1 \\
\hline 1997 & Globalização ética e solidariedade (artigo) & 4 \\
\hline 1997 a & Pedagogia da Autonomia: saberes necessários à prática educativa & 1 \\
\hline 2007 & Política e educação & 1 \\
\hline Livros e capítulos de outros autores relacionados às teorias freireanas & $\begin{array}{l}\text { O ensino de Física e a concepção freiriana da educação } \\
\text { (Demetrio Delizoicov) }\end{array}$ \\
\hline 1983 & \\
\hline
\end{tabular}




\begin{tabular}{|c|l|c|}
\hline 1983 & $\begin{array}{l}\text { Pedagogia dialética: de Aristóteles a Paulo Freire (Wolfdietrich } \\
\text { Schmiedt-Kowarzik) }\end{array}$ & 1 \\
\hline 1986 & O que é o método Paulo Freire (Carlos Rodrigues Brandão) & 1 \\
\hline 1997 & $\begin{array}{l}\text { Da ação à operação: o caminho da aprendizagem em Jean Piaget } \\
\text { (Fernando BECKER) }\end{array}$ & 1 \\
\hline 1998 & $\begin{array}{l}\text { Apontamentos para uma crítica das repercussões da obra de Paulo } \\
\text { Freire (José Sérgio Fonseca de Carvalho) }\end{array}$ & 1 \\
\hline 1999 & $\begin{array}{l}\text { Dicionário "Paulo Freire" (Maria de Lourdes Fávero e Jader M. } \\
\text { Britto). }\end{array}$ & 1 \\
\hline 2000 & Paulo Freire e o nacional desenvolvimentismo (Vanilda Paiva) \\
\hline 2002 & $\begin{array}{l}\text { Educação e democracia? A práxis de Paulo Freire em São Paulo } \\
\text { (Carlos Alberto Torres, María Pilar O'Cadiz e Pia Lindquist Wong). }\end{array}$ & 1 \\
\hline 2003 & \begin{tabular}{l} 
Práticas freirianas no ensino de ciências (Demetrio Delizoicov) \\
\hline
\end{tabular}
\end{tabular}
Elaboração das autoras. Fonte: Cadernos de Indicadores da Capes.

\section{Considerações Finais}

O olhar contextualizado nas transformações históricas e sociais aproxima a pedagogia de Paulo Freire e o Ensino de Ciências, fazendo com que a própria ciência seja questionada e seu ensino problematizado. Os marcos históricos, a força produtiva e a globalização que hoje se estabelecem pelo avanço das tecnologias da informação e comunicação transformaram modos de vida, visões de mundo e formas de ensinar, que inspiradas na pedagogia freireana questionam a hegemonia da ciência, como um conhecimento pretensamente neutro.

Os resultados apresentados nesse estudo indicam que a Educação CTS estabelece ligações concretas com a pedagogia de Paulo Freire por meio da utilização do seu referencial teórico nas teses e dissertações, bem como em disciplinas de pós-graduação. A ligação Freire/CTS se estabelece como campos complementares de forma a atualizar e inserir o Movimento CTS no contexto da educação brasileira, configurando um campo de pesquisa em construção, situado em instituições de renome, como UFSC, USP e UnB.

\section{Referências}

AULER, D; DELIZOICOV, D. Ciência-Tecnologia-Sociedade: relações estabelecidas por professores de ciências. Revista Electrónica de Enseñanza de las Ciencias, v. 5, n. 2, p. 337-355, 2006a.

AULER, D.; DELIZOICOV, D. Educação CTS: Articulação entre Pressupostos do Educador Paulo Freire e Referenciais Ligados ao Movimento CTS. In: Seminário Ibérico CTS no ensino das ciências: las relaciones CTS en la Educación Científica, 4., 2006, Málaga. Anais...Málaga: Universidad de Málaga, 2006b. p. 1-7.

AULER, D.; DALMOLIN, A. M. T.; FENALTI, V. S. Abordagem Temática: natureza dos temas em Freire e no Enfoque CTS. Alexandria - Revista de Educação em Ciência e Tecnologia, Florianópolis, v. 2, n. 1, p. 67-84, 2009.

BECKER, F. Da ação à operação: o caminho da aprendizagem; J. Piaget e P. Freire. 2.ed. Rio de Janeiro, 1997.

BRANDÃO, C. R. O que é o método Freire. São Paulo: Ed. Brasiliense, 1986. 
CAPECE, J. A. O resgate do saber das comunidades locais na melhoria da qualidade do ensino de Ciências Naturais do $1^{\circ}$ Grau do nível primário em Moçambique. Tese (Doutorado em Educação-Currículo). São Paulo: PUC-SP, 2001.

CARVALHO, J. S. F. Apontamentos para uma crítica das repercussões da obra de Paulo Freire. Cadernos de História e Filosofia da Educação, São Paulo, v. 2, n. 4, p. 23-33, 1998.

COORDENAÇÃO DE APERFEIÇOAMENTO DE PESSOAL DE NÍVEL SUPERIOR CAPES. MEC. Banco de teses. Disponível em: <http://www.capes.gov. br/servicos/bancode-teses>.Acesso em: $10 \mathrm{de} \mathrm{fev.} 2013$.

COORDENAÇÃO DE APERFEIÇOAMENTO DE PESSOAL DE NÍVEL SUPERIOR CAPES. MEC. Cursos recomendados. Disponível em: < http://www.capes.gov.br/cursosrecomendados>. Acesso em: 10 de fev. 2013.

CRUZ, C. C. Uma proposta de formação técnico-humanista aplicada ao ensino de Engenharia Elétrica. Dissertação (Mestrado em Engenharia Elétrica). Campinas: Unicamp, 2002.

CUNHA, A. V. Considerações sobre os aspectos cinemáticos e dinâmicos do movimento. Dissertação (Mestrado em Educação para a Ciência). Bauru: Unesp, 2008.

DELIZOICOV, D.; AULER, D.; Ciência, Tecnologia e Formação Social do Espaço: questões sobre a não-neutralidade. Alexandria: Revista de Educação em Ciência e Tecnologia, v.4, n.2, p.247-273, novembro 2011.

DELIZOICOV, D. Práticas freirianas no ensino de ciências. In: Matos, C. (org.) Conhecimento Científico e Vida Cotidiana. São Paulo: Terceira Margem/Estação Ciência, 2003.

DELIZOICOV, D. O ensino de física e a concepção freriana da educação. Revista de Ensino de Física. São Paulo, v. 5, n. 2, 1983.

DURANT, J. Participatory technology assessment and the democratic model of the public understanding of science. Science and Public Policy, v. 26, n. 5, p. 313-319, 1999.

FÁVERO, M. L.A; BRITTO; J.M. "Paulo Freire" - Dicionário de Educadores no Brasil. Rio de Janeiro: Editora UFRJ/MEC/INEP, 1999.

FONSECA, M. S. A ênfase curricular CTS - Ciência, Tecnologia e Sociedade - nos livros didáticos de Ciências no Brasil. Dissertação (Mestrado em Educação Tecnológica). Belo Horizonte: CEFET/MG, 2008.

FREIRE, P. Educação e sociedade brasileira. Recife, 1959. (Tese de concurso) Educação como prática de liberdade. Rio de Janeiro: Paz e Terra, 1968.

Conscientização: uma introdução ao pensamento de Paulo Freire. São Paulo, Editora Cortez e Moraes, 1979a.

Educação e mudança. Rio de Janeiro: Paz e Terra, 1979b.

Ação cultural para a liberdade e outros escritos. Rio de janeiro: Paz e Terra, 
1981.

Pedagogia do Oprimido. Rio de Janeiro: Paz e Terra, 1983a.

Extensão ou Comunicação? Rio de Janeiro: Paz e Terra, 1983 b.

A educação na cidade. São Paulo: Cortez Editora,1991.

Pedagogia da Esperança: um reencontro com a Pedagogia do Oprimido. Rio de Janeiro: Paz e Terra, 1992.

Pedagogia da autonomia: saberes necessários à prática educativa. São Paulo, Paz e Terra, 1997a.

Globalização ética e solidariedade. In DOWBOR, L.; IANNI, O.; RESENDE, E. A. Desafios da globalização. Rio de Janeiro: Vozes, 1997b.

À sombra desta mangueira. São Paulo: 2001b

Política e educação. São Paulo, Cortez, 2007.

GADOTTI, M. (Org). Paulo Freire: uma biobibliografia. São Paulo: Cortez Editora, 1996.

GADOTTI, S.; FREIRE, P.; GUIMARÃES, S. Pedagogia: diálogo e conflito. São Paulo: Cortez, 1995.

GEHLEN, S. T. Temas e situações significativas no ensino de ciências: contribuições de Freire e Vigotski. Dissertação (Mestrado em Educação nas Ciências). Santa Maria: UNIJUI, 2006

GEHLEN, S. T. A função do problema no processo ensino-aprendizagem de ciências: contribuições de Freire e Vygotsky. Tese (Doutorado em Educação Científica e Tecnológica). Florianópolis: UFSC, 2009.

GLÄNZEL, W. Bibliometrics as a research field: a course on theory and application of bibliometrics indicators. 2003. Disponível em: <www.norslis.net/2004/Bib_Module_KUL.pdf>. Acesso em: 7 mar. 2013.

GUIMARÃES, E. M. Pensando a educação ambiental com referência à teoria de Humberto Maturana: a vivência do espaço relacional na comunidade de Samambaia. Tese (Doutorado em Desenvolvimento Sustentável). Brasília: UnB, 2004.

HAYASHI, M. C. P. I.; FERREIRA JUNIOR, A.; BITTAR, M.; HAYASHI, C. R. M.; SILVA, M. R. da. História da educação brasileira: a produção científica na biblioteca eletrônica SCIELO. Educação \& Sociedade, v. 29, p. 181-211, 2008.

IBICT/MCT. Instituto Brasileiro de Informação em Ciência e Tecnologia. Ministério de Ciência, Tecnologia e Inovação. Biblioteca Digital de Teses e Dissertações. Disponível em: <http://www.ibict.br/informacao-para-ciencia-tecnologia-e-inovacao\%20/bibliotecadigital-Brasileira-de-teses-e-dissertacoes-bdtd> Acesso em abril de 2013.

KRASILCHIK, M. O professor e o currículo das ciências. São Paulo: EPU, 1987.

Reformas e realidade: o caso do ensino das ciências. São Paulo em Perspectiva, São Paulo, v. 14, n. 1, p. 85-93, mar. 2000. 
MARTINS, W. S. Educação de jovens e adultos: proposta de material didático para o Ensino de Química. Dissertação (Mestrado Profissionalizante em Educação). Brasília: UnB, 2007.

MENEZES, L. C. de. Paulo Freire e os físicos. In: GADOTTI, M. (Org). Paulo Freire: uma biobibliografia. São Paulo: Cortez Editora, 1996, p. 639-642.

MUENCHEN, C. Configurações curriculares mediante o enfoque CTS: desafios a serem enfrentados na EJA. Dissertação (Mestrado em Educação). Florianópolis: UFSC, 2006.

MUENCHEN, C. A disseminação dos três momentos pedagógicos: um estudo sobre práticas docentes na região de Santa Maria/RS. Tese (Doutorado em Educação Científica e Tecnológica). Florianópolis: UFSC, 2010.

NASCIMENTO, T.G.; VON LINSINGEN, I. Articulações entre o enfoque CTS e a pedagogia de Paulo Freire como base para o ensino de ciências. Convergência, Toluca, v. 13, p. 95-116, 2006.

NASCIMENTO, T. G. Leituras de divulgação científica na formação inicial de professores de ciências. Tese (Doutorado em Educação Científica e Tecnológica). Florianópolis: UFSC, 2008.

OLIVEIRA, M. L. de. O trabalho pedagógico dos professores do ensino fundamental no ciclo II sobre educação ambiental Recife - PE. Dissertação (Mestrado em Ensino de Ciências). Recife: UFRPE, 2005.

OSORIO, C. La participación pública en sistemas tecnológicos: Lecciones para la educación CTS. Revista CTS, n. 6, v. 2, p. 159-172, Diciembre, 2005.

PAIVA, V. P. Paulo Freire e o nacional desenvolvimentismo. São Paulo: Graal, 2000.

PEREIRA, K. C. Sexualidade na adolescência: trabalhando a pesquisa-ação com referenciais teórico-metodológicos de Paulo Freire. Dissertação (Mestrado em Enfermagem Psiquiátrica). Ribeirão Preto: USP, 2007.

PORTAL Domínio Público. Disponível em:< http://www.dominiopublico.gov.br >Acesso em abr. 2013.

QUEIROZ, A. M. D. Universidade extramuros: concepções da extensão Unimontes e sua relação com o desenvolvimento social regional: 1962-2008. Dissertação (Mestrado em Desenvolvimento Social). Montes Claros: UNIMONTES, 2009.

RIBEIRO, R. A. Divulgação científica e ensino de física: intenções, funções e vertentes. Dissertação (Mestrado em de Ciências: Física, Química e Biologia). São Paulo: USP, 2007.

ROMÃO, J.E. Pedagogia Dialógica. São Paulo: Cortez Editora, 2007.

SANTOS, W. L. P. Aspectos sócio-científicos em aulas de Química. Tese (Doutorado em Educação). Belo Horizonte: UEMG, 2002.

SANTOS, W.L.P. Educação científica humanística em uma perspectiva freireana: resgatando a função do ensino de CTS. Alexandria: Revista de Educação em Ciência e Tecnologia, v.1, n.1, p. 109-131, mar. 2008. 
SANTOS, W. L. P.; MORTIMER, E. F. Uma análise de pressupostos teóricos da abordagem C-T-S (Ciência-Tecnologia-Sociedade) no contexto da educação brasileira. Ensaio: pesquisa em educação em ciências, v. 2, n. 2, p. 133-162, 2002.

SCHMIEDT-KOWARZIK, W. Pedagogia dialética: de Aristóteles a Paulo Freire. São Paulo, Brasiliense, 1983.

SILVA, M. R.; HAYASHI, C. R. M.; HAYASHI, M. C. P. I. Análise bibliométrica e cientométrica: desafios aos especialistas que atuam no campo. InCID: Revista de Ciência da Informação e Documentação, v. 2, p. 110-129, 2011.

SILVEIRA, T. de A. Um curso de evolução das ideias da Física para alunos iniciantes de Licenciatura em Física. Dissertação (Mestrado Profissionalizante em Ensino). Belo Horizonte: PUC-MG, 2008.

STRIEDER, R. B. Abordagem CTS e ensino médio: espaços de articulação. Dissertação (Mestrado em Ensino de Ciências). São Paulo: USP, 2008.

THELWALL, M. Bibliometrics to webometrics. Journal of Information Science, v. 34, n. 4, p. 605-621, 2008.

TORRES, C.A. ,O. CADIZ, M. P. e WONG, P.L. Educação e democracia? A práxis de Paulo Freire em São Paulo. São Paulo: Cortez: Instituto Paulo Freire, 2002.

ZAUITH, G.; OGATA, M.N.; HAYASHI, M. C. P. I. Um breve panorama sobre a Educação CTS no Brasil. In: HOFFMANN, W. A. M. (Org.). Ciência, tecnologia e sociedade: desafios da construção do conhecimento. São Carlos: Edufscar, 2011. p. 2138.

ZAUITH, G.; HAYASHI, M. C. P. I. A perspectiva freireana e o movimento CTS: um recorte a partir do Google Acadêmico. In: Simpósio Nacional de Tecnologia e Sociedade, 4, 2011, Anais...., Curitiba, 2011a. p.1-11.

ZAUITH, G.; HAYASHI, M. C. P. I. A apropriação do referencial teórico de Paulo Freire nos estudos sobre educação CTS. Revista Brasileira de Ciência, Tecnologia e Sociedade, v.2, n.1, p. 278-292, jan./jun. 2011b.

Notas

${ }^{1}$ Graduada em Comunicação Social com habilitação em Jornalismo pela Universidade de Ribeirão Preto (1999). Mestre em Ciência, Tecnologia e Sociedade (PPGCTS/UFSCar). Doutoranda em Educação pela UFSCar

${ }^{2}$ Mestre (1986) e Doutora (1995) em Educação pela Universidade Federal de São Carlos. Professora Associada do Departamento de Ciência da Informação e docente do Programa de Pós-Graduação em Educação, ambos da Universidade Federal de São Carlos. É bolsista de Produtividade em Pesquisa do CNPq.

${ }^{3}$ Estudos brasileiros no campo CTS utilizam as nomenclaturas Educação CTS e Ensino CTS. Entretanto no presente artigo optou-se em utilizar o termo Educação CTS. São conceitos diferentes que se complementam. Teoricamente, a educação é um conceito amplo, a ação de desenvolver as faculdades psíquicas, intelectuais e morais. Já o ensino é uma forma sistemática normal de transmitir conhecimentos, particularmente em escolas. Recebido:Fevereiro-2013

Aprovado: Março-2013 